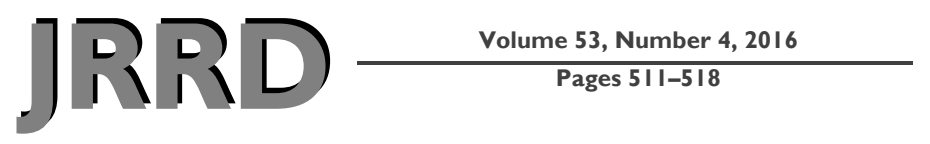

\title{
Validity of the 8-Foot Up and Go, Timed Up and Go, and Activities- Specific Balance Confidence scale in older adults with and without cognitive impairment
}

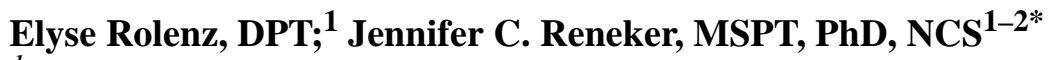 \\ ${ }^{1}$ Louis Stokes Cleveland Department of Veterans Affairs Medical Center, Community Outpatient Services, Akron, OH; \\ ${ }^{2}$ Division of Health Sciences, Physical Therapy Program, Walsh University, North Canton, OH
}

\begin{abstract}
The purpose of this study was to determine whether (1) mild cognitive impairment (MCI) alters the validity of the Timed Up and Go (TUG), the 8-Foot Up and Go (8UG), or the Activities-Specific Balance Confidence (ABC) scale in the identification of fallers and nonfallers and (2) there were differences in the concurrent validity between the TUG and $\mathrm{ABC}$ when compared with the $8 \mathrm{UG}$ and $\mathrm{ABC}$ in those with and without MCI. The classification of MCI was based on a score of $<26$ points on the Montreal Cognitive Assessment. For the 62 participants enrolled, excellent correlations were demonstrated in pairwise comparisons between the outcome measures (on a continuous scale). Based on frequently cited cutpoints, the sensitivity of the TUG was only $20 \%$, with a specificity of $94.6 \%$, and the sensitivity of the $8 \mathrm{UG}$ was $64 \%$, with a specificity of $75.7 \%$. The TUG identified fallers at significantly different rates than the $8 \mathrm{UG}$ and the $\mathrm{ABC}(p<0.05)$. For this reason, the $8 \mathrm{UG}$ is recommended as a more appropriate outcome measure for identifying fall risk in communitydwelling older adults. Fall history was found as the only significant predictor of test outcome for the TUG, $8 \mathrm{UG}$, and $\mathrm{ABC}$, indicating that MCI is not a significant determinant of test performance.
\end{abstract}

Key words: 8-Foot Up and Go, Activities-Specific Balance Confidence scale, community-dwelling older adults, concurrent validity, fall risk, geriatrics, mild cognitive impairment, Montreal Cognitive Assessment, psychometric research, Timed Up and Go.

\section{INTRODUCTION}

Falls are a major health concern for communitydwelling older adults, affecting one out of three people over age 65 yr annually [1]. Falls adversely affect function, result in excessive healthcare costs, and are associated with frailty and death [2-3]. A second health concern common in community-dwelling older adults is mild cognitive impairment (MCI). It has been estimated that $\mathrm{MCI}$ is present in 16 percent of the population over the age of $70 \mathrm{yr}$, most predominantly in men [4]. MCI is considered an intermediary state between the normal cognitive changes of aging and the earliest clinical features of dementia, particularly Alzheimer disease [5]. In addition to memory deficits, MCI has been found to

Abbreviations: $8 \mathrm{UG}=8$-Foot $\mathrm{Up}$ and $\mathrm{Go} ; \mathrm{ABC}=$ ActivitiesSpecific Balance Confidence (scale); $\mathrm{CBOC}=$ Community Based Outpatient Clinic; ICF = International Classification of Functioning, Disability, and Health; LSCVAMC = Louis Stokes Cleveland Department of Veterans Affairs Medical Center; $\mathrm{MCI}=$ mild cognitive impairment; $\mathrm{MoCA}=$ Montreal Cognitive Assessment; TUG $=$ Timed Up and Go; VA = Department of Veterans Affairs.

*Address all correspondence to Jennifer C. Reneker, MSPT, PhD, NCS; Louis Stokes Cleveland VA Medical Center, Akron CBOC-Community Outpatient Services, 75 West Waterloo Rd, Akron, OH 44319; 330-724-7715, ext 2200; fax: 330-724-1501. Email: Jennifer.Reneker@va.gov http://dx.doi.org/10.1682/JRRD.2015.03.0042 
adversely affect temporal orientation, motor initiation, and executive functions relating to planning and working memory, all of which could affect risk for falls [5].

To identify fall risk, medical professionals use various outcome measures to assist with assessment and treatment planning and to quantify change over time [6]. A comprehensive falls risk assessment should include outcome measures from more than one domain within the International Classification of Functioning, Disability, and Health (ICF), including body structure and function and activity and participation [7]. When considering the usefulness of outcome measures in a geriatric population, it is important to recognize the impact that cognitive impairment may have on their validity and reliability. There is some evidence to suggest a negative influence of impaired cognition on outcome measure interpretability; however, the literature is insufficient to draw strong conclusions [8].

The Timed Up and Go (TUG) is one of the most commonly used outcome measures to assess fall risk in the elderly population [9]. Within the activity domain of the ICF, the TUG is a quick objective measure to assess dynamic balance and mobility, integral pieces of a geriatric assessment. The original version of the TUG has been critiqued because of the potential for confusion associated with its instructions regarding the line on the floor [10]. To address this limitation, Rikli and Jones modified the TUG to the 8-Foot Up and Go (8UG), reducing the distance to $8 \mathrm{ft}$ and replacing the line on the floor with a cone to signal the turn-around [10]. It is not known whether these modifications affect test performance differently in people with MCI versus those without MCI.

Within the participation domain of the ICF, the Activities-Specific Balance Confidence (ABC) scale is also frequently used to quantify fall risk. Scoring the $\mathrm{ABC}$ is not based on physical performance, but rather is determined by patient report of his or her confidence while performing a variety of functional activities. Despite the fact that the TUG measures physical performance and the $\mathrm{ABC}$ measures confidence, these outcome measures are strongly correlated [11-12]. The correlation between the $\mathrm{ABC}$ and the $8 \mathrm{UG}$ has not been described.

Although the TUG, 8UG, and $\mathrm{ABC}$ are widely used within the geriatric population, it is unknown whether MCI affects the validity and interpretability of the measures and whether this effect is similar across these measures of activity and participation. Therefore, the purpose of this study was to determine whether MCI alters the validity of the TUG, the $8 \mathrm{UG}$, or the $\mathrm{ABC}$ in the identifi- cation of fallers versus nonfallers. Secondarily, we were interested in determining whether there were differences in the concurrent validity between the TUG and $\mathrm{ABC}$ versus the $8 \mathrm{UG}$ and $\mathrm{ABC}$ in those with and without MCI.

\section{METHODS}

This study was performed as a cross-sectional study. It was approved by the Louis Stokes Cleveland Department of Veterans Affairs (VA) Medical Center (LSCVAMC) Institutional Review Board. Based on previous literature describing the strong correlation (nearly 0.70 ) between the TUG and the $\mathrm{ABC}$ [11], we assumed that the correlation between the $8 \mathrm{UG}$ and the $\mathrm{ABC}$ would be similar. Although not described in previous reports, based on the similarity between the TUG and the 8UG, we believed that the correlation would be 0.50 or greater. Based on this, the sample size was calculated for the primary hypotheses with the following assumptions: probability of type 1 error $(\alpha)$ set at 0.05 , power $(\beta)$ set at 0.90 , and correlation $(\rho)$ set at 0.50 . Given these assumptions, a sample of 62 people was needed for this study.

Subjects were recruited through convenience sampling at the Akron Community Based Outpatient Clinic (CBOC) of the LSCVAMC. Veteran patients and their spouses who visited the CBOC during the time the study was being conducted were asked to participate. Patients were included if they were $65 \mathrm{yr}$ of age or older and living in the community (noninstitutionalized). If a patient self-reported any of the following diagnoses, they were excluded from participation: history of a stroke, traumatic brain injury, Parkinson disease, amyotrophic lateral sclerosis, multiple sclerosis, rheumatoid arthritis, or lower-limb joint replacement within the past 6 mo. These exclusionary diagnoses were chosen because they have been used previously in outcome measure research on community-dwelling older adults to establish more homogenous patient characterization $[5,13]$.

A second measure of eligibility for the study was the identification of fallers and nonfallers through a selfreported falls history. For the purposes of this study, a fall was defined as "any event resulting in an individual unintentionally coming to rest on the ground, floor, or other lower level, not as the result of a major intrinsic event or overwhelming hazard. This includes: slips, trips, falling into other people, being involuntarily lowered, loss of balance, and legs giving way" [13-15]. Based on the 
criterion for the identification of fallers and nonfallers in other outcome measures literature [13-14], participants were considered nonfallers if they reported no incidents of a fall in the past year and were considered fallers if they reported two or more falls in the past year according to the standardized definition provided. Those with a history of one fall in the past year were excluded to maximize the identification of "true" fallers. It has been argued that a patient report of two or more falls is more strongly linked with a predisposition for falling than a single isolated fall [13-14,16-17].

\section{Outcome Measures}

The Montreal Cognitive Assessment (MoCA) is a 30-point standardized outcome measure used clinically to screen for milder forms of cognitive impairment. This test evaluates memory, language, and executive functioning [18-19]. A cutoff score of $<26$ has been suggested to indicate $\mathrm{MCI}$, with a specificity of 87 percent and a sensitivity of 90 percent [19]. We administered the MoCA to differentiate between individuals with normal cognition (scoring $\geq 26$ ) and those with some form of cognitive impairment in this sample of community-dwelling older adults.

The $\mathrm{ABC}$ is a self-report outcome measure used to measure confidence during participation in life activities [20]. Participants were required to indicate their level of self-confidence on a 0-100 percent Likert scale according to the following question: "How confident are you that you will not lose your balance or become unsteady while ... ?" In this manner, they rated their confidence in the ability to complete 16 activities. The score for the $\mathrm{ABC}$ was obtained by adding each score for each item and dividing by 16 to obtain the mean, which is reported as the total score. A score of $\leq 67$ percent was used as predictive of fallers [11,21].

The TUG is a timed test that requires the participant to stand up from a chair with armrests, walk $3 \mathrm{~m}$ (9.86 ft) to a line on the floor, turn around, return to the chair, and sit down. Research has suggested that a cutoff time of $13.5 \mathrm{~s}$ should be used as a threshold for identifying persons with an increased risk of falling $[5,9,14]$. Although other cutoff times have been suggested, this cutoff time is the most widely accepted for indicating fall risk in community-dwelling older adults [9].

The $8 \mathrm{UG}$ is a timed test that requires one to stand up from a chair with armrests, walk to a cone $8 \mathrm{ft}$ away, turn around, return to the chair, and sit down. Research has suggested that a cutoff time of $8.5 \mathrm{~s}$ should be used as a threshold for identifying persons with an increased risk of falling $[13,21]$.

\section{Procedure}

Once participants were enrolled in the study, the TUG and the $8 \mathrm{UG}$ were administered. All of the testing was completed in a private, controlled environment to minimize environmental distractions. Based on alternating even and odd study identification numbers, half of the participants performed the 8UG first followed by the TUG and the other half performed the TUG followed by the 8UG to avoid test-order effects [19]. The ABC and MoCA were administered in-between the two walking tests to permit at least $10 \mathrm{~min}$ of rest before the second test, thereby reducing the potential for fatigue-induced performance differences.

Participants were provided with standardized verbal instructions for both the TUG and the 8UG, one demonstration, and one practice trial followed by two timed trials. The verbal instructions in this present study were the same as those used by Rose et al. [13] and those reported in the development of the original TUG test [22]. For the TUG, these instructions were "When I say 'go,' I want you to stand up and walk to the line as quickly and safely as possible, turn around, walk back, and sit down in the shortest time possible." For the $8 \mathrm{UG}$, these instructions were identical with the exception of turning around at the cone instead of the line [13]. The time taken to complete each test was measured in seconds with a stopwatch, began with the command "go," and stopped at the moment the participant's buttocks contacted the chair. Participants were permitted to use their hands to rise from or lower themselves onto the chair, and an assistive device could also be used to complete the test. No physical assistance was provided to participants.

\section{Statistical Analysis}

All statistical analyses were completed with SAS version 9.3 (SAS Institute Inc; Cary, North Carolina). Descriptive statistics were completed for the entire sample and for the subgroups with and without MCI. Chisquare tests were used for falls (yes/no) and for sex (male/female), and a $t$-test was used for age to establish whether there were differences between those with and without MCI in these demographic variables.

In order to describe the effect of MCI on test outcomes, independent $t$-tests were completed to compare 
the time in seconds for the completion of the $8 \mathrm{UG}$ and the TUG and the total score on the ABC between those with MCI and those without MCI. To account for potential confounding on the outcome for the TUG, 8UG, and $\mathrm{ABC}$ (separately), we conducted multiple linear regression, adding age, fall history, and sex to the model.

Sensitivity and specificity for the identification of fallers was calculated for each test by MCI status. In addition, the McNemar test was used to determine whether the rate of identification of fallers and nonfallers (as per the most frequently cited cutpoints) were the same for the two tests in each pairwise comparison (8UG and TUG, $8 \mathrm{UG}$ and $\mathrm{ABC}$, and TUG and $\mathrm{ABC}$ ). The $p$-values obtained indicate whether the marginal frequencies are different (indicating that tests indicate fallers and nonfallers at different rates). The kappa statistic was also calculated, indicating the overall percent agreement between the outcome measures.

To define the concurrent validity of the $8 \mathrm{UG}$ to the TUG, the $8 U G$ to the $A B C$, and the TUG to the ABC, we conducted pairwise Pearson correlation coefficients. As per the conventional test protocols and scoring directions for each outcome measure, the fastest recorded time from the two timed trials was used for the TUG, the average time for the two timed trials was used for the $8 \mathrm{UG}$, and the average of the 16 scored items for the $\mathrm{ABC}$ was used for all analyses completed. Correlations were completed for the entire sample and for the subgroups based on MCI. The interpretation of the strength of the calculated coefficients was as follows: excellent $(r>0.6)$, adequate $(r=0.31-0.59)$, and poor $(r<0.30)$ [9].

\section{RESULTS}

Sixty-two participants enrolled in the study and completed the research protocol. The descriptive statistics for the sample are presented in Table 1. The sample included 41 males and 21 females. Of the 62 patients, 25 selfreported two or more falls in the previous $12 \mathrm{mo}$ and were identified as fallers and 37 denied any falls in the past $12 \mathrm{mo}$ and were identified as nonfallers. After completion of the MoCA, 41 participants scored $<26$ points and were classified as having MCI. The mean age for the sample was just under $74 \mathrm{yr}$ of age. There was a significant difference in age between those with MCI and those without MCI.
Table 1.

Descriptive statistics for sample.

\begin{tabular}{|c|c|c|c|}
\hline Characteristic & $\begin{array}{c}\text { MCI } \\
(n=41)\end{array}$ & $\begin{array}{l}\text { No MCI } \\
(n=21)\end{array}$ & $p$-Value \\
\hline \multicolumn{4}{|l|}{ Age (yr) } \\
\hline Mean \pm SD & $75.4 \pm 8.3$ & $70.1 \pm 5.7$ & \multirow[t]{2}{*}{0.01} \\
\hline Range & 65-90 & $65-88$ & \\
\hline \multicolumn{4}{|l|}{ Sex, $n(\%)$} \\
\hline Male & $26(63.4)$ & $15(71.4)$ & \multirow[t]{2}{*}{0.53} \\
\hline Female & $15(36.6)$ & $6(28.6)$ & \\
\hline \multicolumn{4}{|l|}{ History of Falls, $n(\%)$} \\
\hline Yes & $17(41.5)$ & $8(38.1)$ & \multirow[t]{2}{*}{0.80} \\
\hline No & $24(58.5)$ & $13(61.9)$ & \\
\hline \multicolumn{4}{|l|}{$\mathrm{MoCA}$} \\
\hline Mean \pm SD & $21.3 \pm 2.7$ & $26.5 \pm 0.9$ & \multirow[t]{2}{*}{$<0.01$} \\
\hline Range & $14-25$ & 26-29 & \\
\hline \multicolumn{4}{|l|}{$\mathrm{TUG}^{*}$} \\
\hline Mean \pm SD & $10.1 \pm 3.6$ & $8.7 \pm 2.7$ & \multirow[t]{2}{*}{0.13} \\
\hline Range & $4.2-20.3$ & $5.5-17.4$ & \\
\hline \multicolumn{4}{|l|}{$8 \mathrm{UG}^{*}$} \\
\hline Mean \pm SD & $9.3 \pm 3.8$ & $7.6 \pm 1.9$ & \multirow[t]{2}{*}{0.03} \\
\hline Range & $4.6-21.1$ & $4.5-10.9$ & \\
\hline \multicolumn{4}{|l|}{$\mathrm{ABC}^{\dagger}$} \\
\hline Mean \pm SD & $72.7 \pm 22.0$ & $81.7 \pm 21.7$ & \multirow[t]{2}{*}{0.13} \\
\hline Range & $15.3-100.0$ & $21.3-100.0$ & \\
\hline \multicolumn{4}{|c|}{$\begin{array}{l}\text { Note: Chi-square tests used to test for differences in binomial variables; } t \text {-tests } \\
\text { used to test for difference in continuous variables. Significance set at } 0.05 \text { for } \\
\text { all variables. } \\
{ }^{*} \text { Measured in seconds to complete. } \\
{ }^{\dagger} \text { Measured in percent confidence. } \\
8 \mathrm{UG}=8 \text {-Foot Up and Go, ABC = Activities-Specific Balance Confidence } \\
\text { (scale), MCI = mild cognitive impairment, MoCA = Montreal Cognitive } \\
\text { Assessment, SD = standard deviation, TUG = Timed Up and Go. }\end{array}$} \\
\hline
\end{tabular}

As a component of the descriptive statistics, the time to complete the TUG and the $8 \mathrm{UG}$ and the mean percentage for the ABC by MCI status is presented in Table 1. The univariate analysis revealed significant differences in the time to complete the 8UG between those with and without MCI $(p=0.03)$. These differences were not observed for the TUG or the score on the ABC (both $p=$ 0.13). Results of multiple linear regression with the potential confounders of age, sex, and fall history demonstrated that fall history was the only significant predictor for the outcome of the TUG, the 8UG, and the ABC ( $p<$ 0.001 in all cases) and that MCI no longer remained a significant predictor of performance on the $8 \mathrm{UG}$ when accounting for fall history.

When considering the measure's ability to correctly classify fallers and nonfallers on the basis of established cutoff times, the results demonstrated that across the groupings (total sample, those with MCI, and those without MCI) the sensitivities and the specificities are similar 
(Table 2). For the total sample, the $8 \mathrm{UG}$ is 64 percent sensitive, 76 percent specific; the TUG is 20 percent sensitive, 95 percent specific; and the $\mathrm{ABC}$ is 89 percent sensitive, 56 percent specific.

The completion of pairwise comparisons of the test's ability to identify fallers and nonfallers by MCI status indicates that the $8 \mathrm{UG}$ and $\mathrm{ABC}$ identify fallers and nonfallers at statistically similar rates in both those with $(\kappa=$ $0.48, p=0.34)$ and those without MCI $(\kappa=0.24, p=$ $0.45)$ (Table 3). However, the TUG identifies fallers at significantly different rates than the 8UG $(\kappa=0.39, p<$ 0.001 for those with MCI and $\kappa=0.15, p=0.01$ for those without $\mathrm{MCI})$ or the $\mathrm{ABC}(\kappa=0.54, p=0.02$ for those with MCI; the rates were statistically similar for those without MCI; $\kappa=0.28, p=0.13$ ).

On a continuous scale, the correlation of the total time in seconds for the 8UG and the TUG demonstrated excellent concurrent validity for those with MCI $(r=$ $0.92, p<0.001)$ and those without MCI $(r=0.85, p<$ 0.001 ) (Table 4). The correlation coefficient of the total time in seconds for the 8UG and the $\mathrm{ABC}$ demonstrated excellent concurrent validity for those with $\mathrm{MCI}(r=-0.63$, $p<0.001)$ but was determined to be adequate for those with no MCI $(r=-0.56, p=0.008)$. The correlation coefficient of the total time in seconds for the TUG and the ABC similarly resulted in excellent concurrent validity for those with MCI $(r=-0.74, p<0.001)$ and those without MCI $(r=-0.64, p<0.001)$.

Despite the unequal distribution of participants (more in the MCI group than in the non-MCI group), this sample and the results of the correlation analysis provide a $>0.90$ power for the aims of this study.

\section{DISCUSSION}

The purpose of this study was to determine whether MCI alters the validity of the TUG, the 8UG, or the ABC in the identification of fallers and nonfallers. Secondarily, we were interested in determining whether there were differences in the concurrent validity between the TUG and $\mathrm{ABC}$ when compared with the $8 \mathrm{UG}$ and $\mathrm{ABC}$ in those with and without MCI. Our results indicate that MCI is not a significant predictor of outcome for the $8 \mathrm{UG}$, the TUG, or the ABC. The sensitivity and specificity of each test was similar for the total sample and for both those with and those without MCI. The percent agreement of each pairwise comparison produced mixed results, with the TUG identifying fallers at significantly different rates than the $8 \mathrm{UG}$ and the $\mathrm{ABC}$. Excellent correlations of the total test score were demonstrated in each

Table 2.

Sensitivity (SN) and specificity (SP) of 8-Foot Up and Go (8UG), Timed Up and Go (TUG), and Activities-Specific Balance Confidence (ABC) scale by mild cognitive impairment (MCI) status for identification of fallers and nonfallers.

\begin{tabular}{|c|c|c|c|c|c|c|}
\hline \multirow{2}{*}{ Test } & \multicolumn{2}{|c|}{ Total Sample $(n=62)$} & \multicolumn{2}{|c|}{$\operatorname{MCI}(n=41)$} & \multicolumn{2}{|c|}{ No MCI $(n=21)$} \\
\hline & SN & SP & SN & SP & SN & SP \\
\hline$\overline{8 \mathrm{UG}}$ & 64.0 & 75.7 & 64.7 & 75.0 & 62.5 & 76.9 \\
\hline TUG & 20.0 & 94.6 & 23.6 & 91.7 & 12.5 & 100.0 \\
\hline $\mathrm{ABC}$ & 89.2 & 56.0 & 87.5 & 58.8 & 92.3 & 50.0 \\
\hline
\end{tabular}

Table 3.

Kappa coefficient for marginal frequencies of 8-Foot Up and Go (8UG) to Timed Up and Go (TUG) and Activities-Specific Balance Confidence $(\mathrm{ABC})$ scale in identifying fallers and nonfallers.

\begin{tabular}{|c|c|c|c|c|c|c|}
\hline \multirow{2}{*}{ Test } & \multicolumn{2}{|c|}{ 8UG } & \multicolumn{2}{|c|}{ ABC } & \multicolumn{2}{|c|}{ TUG } \\
\hline & MCI & No MCI & MCI & No MCI & MCI & No MCI \\
\hline $8 \mathrm{UG}$ & 1.0 & 1.0 & - & - & - & - \\
\hline $\mathrm{ABC}$ & $0.48(p=0.34)$ & $0.24(p=0.45)$ & 1.0 & 1.0 & - & - \\
\hline TUG & $0.39(p<0.001)$ & $0.15(p=0.01)$ & $0.54(p=0.02)$ & $0.28(p=0.13)$ & 1.0 & 1.0 \\
\hline
\end{tabular}

Note: McNemar test statistic was used to determine whether tests identify fallers at different rates based on specified cutpoints. Kappa statistic presented to indicate percent agreement.

$\mathrm{MCI}=$ mild cognitive impairment. 
JRRD, Volume 53, Number 4, 2016

Table 4.

Correlation matrix of score in seconds of 8-Foot Up and Go (8UG), Timed Up and Go (TUG), and average score of Activities-Specific Balance Confidence (ABC) scale by mild cognitive impairment status (MCI).

\begin{tabular}{|c|c|c|c|c|c|c|}
\hline \multirow{2}{*}{ Test } & \multicolumn{2}{|c|}{ 8UG } & \multicolumn{2}{|c|}{ ABC } & \multicolumn{2}{|c|}{ TUG } \\
\hline & MCI & No MCI & MCI & No MCI & MCI & No MCI \\
\hline$\overline{8 U G}$ & & & \multicolumn{2}{|c|}{-} & \multicolumn{2}{|c|}{-} \\
\hline $\mathrm{ABC}$ & -0.63 & -0.56 & \multicolumn{2}{|c|}{1.0} & \multicolumn{2}{|c|}{ - } \\
\hline TUG & 0.92 & 0.85 & -0.74 & -0.64 & \multicolumn{2}{|c|}{1.0} \\
\hline
\end{tabular}

pairwise comparison between the $8 \mathrm{UG}$, the TUG, and the $\mathrm{ABC}$ (with the exception of an adequate correlation between the $8 \mathrm{UG}$ and the $\mathrm{ABC}$ in those without $\mathrm{MCI}$ ).

In our sample, cognitive status did not significantly affect the validity of any of the three tests or produce divergent identification of fallers and nonfallers across tests from different domains of the ICF. Despite this, a surprising result was the poor sensitivity $(20 \%)$ of the TUG and that the TUG had poor agreement with the $8 \mathrm{UG}$ and the $\mathrm{ABC}$ in the identification of fallers. These findings persisted in those participants with and without MCI. This is similar to findings in a previous study by Rose et al. [13], where the $13.5 \mathrm{~s}$ cutoff time for the TUG incorrectly classified 45 out of 63 community-dwelling older adults as nonfallers when they were in fact recurrent fallers. Based on this error in classification, Rose and colleagues suggested a cutoff time of $10.0 \mathrm{~s}$ for the TUG, resulting in sensitivity and specificity values of 71 percent and 89 percent, respectively [13]. Although the objective of our research was not to propose another cutoff time for the TUG, our findings confirm that a faster cutoff score would make the TUG a more valid test than the currently used time of $13.5 \mathrm{~s}$.

Considering the concurrent validity of the $8 \mathrm{UG}$ with the $\mathrm{ABC}$ and the TUG with the ABC, our findings demonstrate that these tests have similar and high inverse relationships. As the time to complete the $8 \mathrm{UG}$ and TUG increases, the patient's perception of balance confidence declines. This relationship is similar in direction and magnitude across MCI status. Although this was the first study to investigate the concurrent validity of the 8UG with the $\mathrm{ABC}$, this finding is similar to the findings of a previous systematic review and meta-analysis that investigated $\mathrm{ABC}$ score and performance on the TUG. The meta-analysis across the included studies produced an excellent correlation between the TUG and the ABC ( $r=$ $-0.698, p<0.01)$, without differentiation in the presence of MCI [11].
It should be noted that in this present study as well as in both studies completed by both Shumway-Cook et. al. [14] and Rose et al. [13], the population consisted of community-dwelling older adults, with similar exclusionary diagnoses and the same test instructions and scoring methods for the TUG. A key difference between these two previous research studies is the sample size; the $13.5 \mathrm{~s}$ cutoff time was based on a sample size of 15 and the $10 \mathrm{~s}$ cutoff time was based on a sample size of 134 [13-14]. Based on this, we confirm that the 8UG and the TUG are useful for identifying community-dwelling older adults with a history of falls when using a cutoff score of $10 \mathrm{~s}$ for the TUG and $8.5 \mathrm{~s}$ for the $8 \mathrm{UG}$.

The limitations of this study include a narrow study sample consisting of a majority of Veteran participants, a disproportional number of males (66.1\%), and individuals screened to have MCI (66.1\%). The classification of MCI was based on the score obtained during the completion of the MoCA. Given that the range of scores for participants in the MCI group ranged from as high as 25 down to 14, it is quite possible that more extreme forms of cognitive impairment are present within the sample than just MCI. Despite this, the results still confirm that within the group of participants screened to have (at least) MCI, these tests demonstrate similar psychometric properties as when used to test those without MCI. Subjective report of falls and past medical history are also limitations because those with cognitive impairment may not provide the most accurate historical information.

It should be pointed out that there are differences in the implementation of the TUG across studies [23]. Some studies have reported using walk at a "normal pace" and others a "fast pace" [23]. These current results are interpreted based on the test with the instructions to walk at a fast pace. It is unknown whether there would be similar findings if the instructions for the TUG would have been to walk at a normal pace. 


\section{CONCLUSIONS}

In conclusion, each outcome measure (TUG, 8UG, and $\mathrm{ABC}$ ) demonstrates similar validity in communitydwelling older adults with and without MCI in the identification of fall risk. MCI is not a significant predictor of outcome for the $8 \mathrm{UG}$, the TUG, or the ABC. The $8 \mathrm{UG}$ has better sensitivity than the TUG when traditional cutoff times are applied. Although the $8 \mathrm{UG}$ and the TUG appear to assess functional performance similarly, the use of $13.5 \mathrm{~s}$ as the cutoff time for the TUG in the identification of fall risk should be questioned. For this reason, the $8 \mathrm{UG}$ with a cutoff time of $8.5 \mathrm{~s}$ is recommended as a more appropriate outcome measure in community-dwelling older adults.

\section{ACKNOWLEDGMENTS}

\section{Author Contributions:}

Study design: E. Rolenz, J. C. Reneker.

Patient enrollment: E. Rolenz, J. C. Reneker.

Data collection: E. Rolenz, J. C. Reneker.

Data analysis: J. C. Reneker.

Drafting of manuscript: E. Rolenz, J. C. Reneker.

Critical revision of manuscript for important intellectual content:

E. Rolenz, J. C. Reneker.

Financial Disclosures: The authors have declared that no competing interests exist.

Funding/Support: This material is based on work supported with resources and the use of facilities at the LSCVAMC.

Additional Contributions: Elyse Rolenz, DPT, has received Geriatric Specialty Certification since completion of the study.

Institutional Review: Institutional review board approval was obtained from the LSCVAMC (\#14016-H09) prior to any participant enrollment or data collection. The protection of human subjects and ethical adherence was maintained throughout the duration of the study.

Participant Follow-up: The authors have no plans to notify the study subjects of the publication of this article because of a lack of contact information.

Disclaimer: The contents do not represent the views of the VA or U.S. Government.

\section{REFERENCES}

1. Stevens JA, Ballesteros MF, Mack KA, Rudd RA, DeCaro E, Adler G. Gender differences in seeking care for falls in the aged Medicare population. Am J Prev Med. 2012; 43(1):59-62. [PMID:22704747] http://dx.doi.org/10.1016/j.amepre.2012.03.008
2. Campbell AJ, Spears GF, Borrie MJ. Examination by logistic regression modelling of the variables which increase the relative risk of elderly women falling compared to elderly men. J Clin Epidemiol. 1990;43(12):1415-20.

[PMID:2254780]

http://dx.doi.org/10.1016/0895-4356(90)90110-B

3. Rubenstein LZ, Josephson KR. The epidemiology of falls and syncope. Clin Geriatr Med. 2002;18(2):141-58.

[PMID:12180240]

http://dx.doi.org/10.1016/S0749-0690(02)00002-2

4. Bennett DA, Wilson RS, Schneider JA, Evans DA, Beckett LA, Aggarwal NT, Barnes LL, Fox JH, Bach J. Natural history of mild cognitive impairment in older persons. Neurology. 2002;59(2):198-205. [PMID:12136057]

http://dx.doi.org/10.1212/WNL.59.2.198

5. Ribeiro F, de Mendonça A, Guerreiro M. Mild cognitive impairment: Deficits in cognitive domains other than memory. Dement Geriatr Cogn Disord. 2006;21(5-6):284-90. [PMID:16484806] http://dx.doi.org/10.1159/000091435

6. Commission on Accreditation in Physical Therapy Education. Evaluative criteria for accreditation of education programs for the preparation of physical therapists. Alexandria (VA): American Physical Therapy Association; 2006.

7. Hart-Hughs S, Reneker J. VA National Center for Public Safety. Balance assessment handbook: A component of the falls toolkit [Internet]. Tampa (FL): James A. Haley Veterans' Hospital; 2014 [updated 2014 May; cited 2014 Dec]. Available from: http://www.patientsafety.va.gov/docs/ fallsToolkit/Balance_Assessment_Handbook.pdf

8. Phillips CD, Chu CW, Morris JN, Hawes C. Effects of cognitive impairment on the reliability of geriatric assessments in nursing homes. J Am Geriatr Soc. 1993;41(2):136-42. [PMID:8426035] http://dx.doi.org/10.1111/j.1532-5415.1993.tb02047.x

9. Dawood A, Raad J. Rehab measures: Timed Up And Go [Internet]. Chicago (IL): Rehab Institute of Chicago; 2010 [updated 2014 Aug 28; cited 2014 Sept]. Available from: http://www.rehabmeasures.org/Lists/RehabMeasures/ DispForm.aspx? ID $=903$

10. Rikli RE, Jones CJ. Development and validation of a functional fitness test for community-residing older adults. J Aging Phys Act. 1999;7(2):129-61.

11. Stansy BM, Newton RA, LoCascio LV, Bedio N, Lauke C, Conroy M, Thompson A, Vakhnenko L, Polidoro C. The $\mathrm{ABC}$ scale and fall risk: A systematic review. Phys Occup Ther Geriatr. 2001;29(3):233-42.

12. Powell LE, Myers AM. The Activities-specific Balance Confidence (ABC) scale. J Gerontol A Biol Sci Med Sci. 1995;50A(1):M28-34. [PMID:7814786] http://dx.doi.org/10.1093/gerona/50A.1.M28 
13. Rose DJ, Jones CJ, Lucchese N. Predicting the probability of falls in community-residing older adults using the 8-foot up-and-go: A new measure of functional mobility. J Aging Phys Act. 2002;10:466-75.

14. Shumway-Cook A, Brauer S, Woollacott M. Predicting the probability for falls in community-dwelling older adults using the Timed Up \& Go Test. Phys Ther. 2000;80(9): 896-903. [PMID:10960937]

15. Tinetti ME, Speechley M, Ginter SF. Risk factors for falls among elderly persons living in the community. N Engl J Med. 1988;319(26):1701-7. [PMID:3205267] http://dx.doi.org/10.1056/NEJM198812293192604

16. Chandler J. Invited commentary. Phys Ther. 1996;76(6): 584-85.

17. Nevitt MC, Cummings SR, Kidd S, Black D. Risk factors for recurrent nonsyncopal falls. A prospective study. JAMA. 1989;261(18):2663-68. [PMID:2709546] http://dx.doi.org/10.1001/jama.1989.03420180087036

18. Waldron-Perrine B, Axelrod BN. Determining an appropriate cutting score for indication of impairment on the Montreal Cognitive Assessment. Int J Geriatr Psychiatry. 2012; 27(11):1189-94. [PMID:22228412] http://dx.doi.org/10.1002/gps.3768

19. Nasreddine ZS, Phillips NA, Bédirian V, Charbonneau S, Whitehead V, Collin I, Cummings JL, Chertkow H. The Montreal Cognitive Assessment, MoCA: A brief screening tool for mild cognitive impairment. J Am Geriatr Soc. 2005;53(4):695-99. [PMID:15817019] http://dx.doi.org/10.1111/j.1532-5415.2005.53221.x

20. Takahashi T, Ishida K, Yamamoto H, Takata J, Nishinaga M, Doi Y, Yamamoto H. Modification of the functional reach test: Analysis of lateral and anterior functional reach in community-dwelling older people. Arch Gerontol Geri- atr. 2006;42(2):167-73. [PMID:16125260]

http://dx.doi.org/10.1016/j.archger.2005.06.010

21. Rikli RE, Jones CJ. Senior fitness test manual. Champaign (IL): Human Kinetics; 2001.

22. Podsiadlo D, Richardson S. The timed "Up \& Go": A test of basic functional mobility for frail elderly persons. J Am Geriatr Soc. 1991;39(2):142-48. [PMID:1991946] http://dx.doi.org/10.1111/j.1532-5415.1991.tb01616.x

23. Schoene D, Wu SM, Mikolaizak AS, Menant JC, Smith ST, Delbaere K, Lord SR. Discriminative ability and predictive validity of the timed up and go test in identifying older people who fall: Systematic review and meta-analysis. J Am Geriatr Soc. 2013;61(2):202-8. [PMID:23350947] http://dx.doi.org/10.1111/jgs.12106

Submitted for publication March 11, 2015. Accepted in revised form September 11, 2015.

This article and any supplementary material should be cited as follows:

Rolenz E, Reneker JC. Validity of the 8-Foot Up and Go, Timed Up and Go, and Activities-Specific Balance Confidence scale in older adults with and without cognitive impairment. J Rehabil Res Dev. 2016;53(4):511-18. http://dx.doi.org/10.1682/JRRD.2015.03.0042

ORCID: Jennifer C. Reneker, MSPT, PhD, NCS: 00000003-3617-5681

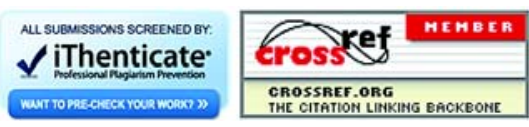

